\title{
Influence of cow urine in the bioavailability of plutonium oxide particles in Palomares soils
}

\author{
A. Espinosa, A. Aragón, B. de la Cruz and J . Gutiérrez \\ Centro de Investigaciones Energéticas Medioambientales y Tecnológicas (CIEMAT), Avda. \\ Complutense 22, 28040 Madrid, Spain
}

\begin{abstract}
The nuclear accident that occurred in Palomares in 1966 caused the release of plutonium weapon grade particles into a Mediterranean ecosystem, and consequently, urban and farming areas were contaminated with this material. Several studies focused on the characterization and behaviour of transuranides have been carried out in the area. In this work, the solubility evolution of plutonium is analysed for a period of more than 30 years, as well as the influence that the incorporation of cow urine into organic fertilizers has on the solubility of the mentioned element. The average value of the plutonium solubility in water determined in five samples was $0.0082 \%$ in 1986 . However, determinations carried out in samples taken in 1999 and 2000 indicated an increase of the plutonium solubility of two orders of magnitude. In order to check the influence of organic fertilizers on the solubility of plutonium, a solubility test was carried out using cow urine as extracting solution. The results show that the solubility of plutonium can reach a value equal to $14 \%$, which is similar to the one obtained with sodium pyrophosphate acting as extracting solution. Thus, these results are a clear warning of what might happen if organic fertilizers are used in transuranic-contaminated soils.
\end{abstract}

\section{INTRODUCTION}

When the solubility of radionuclides in soils is determined, the estimation of the amount that can be incorporated to vegetables through their roots (root uptake) is very important, as well as its mobility in soils. Most studies related to plutonium oxide incorporated to vegetables agree that the absorption through roots is very low, and sometimes an aerial deposit can be found, being an aerial deposit of the elements and their incorporation via stomata (gases) and via the cuticle (ions) more significant [1,2 and 3].

The aqueous phase concentration of plutonium is usually controlled by the presence of $\mathrm{Pu}(\mathrm{OH})_{4}(\mathrm{~s})$ or $\mathrm{PuO}_{2}$ because of the extremely low solubility of these compounds; nevertheless, a recent study [4] shows that the plutonium solubility can change due to the environmental conditions, possibly because of the fact that the solubility changes of plutonium oxide depend on the oxidation state. [5] have found that the plutonium solubility has increased 96 times in 13 years (from 1986 to 1999). This author considers that this significant increase has been caused by the change of humid conditions in the area of Palomares and by the reduction of the particle sizes due to their fragmentation.

The intense agricultural practice demanded by the world market makes the use of fertilizers necessary, due to the natural lack of nutrients. The massive use of chemicals degrades the soil, thus, in order to mitigate this degradation and mineralise the soil, the addition of organic fertilizers is necessary, being the liquid and solid animal excrements (manure) the most used.

All these agricultural activities have caused physico-chemical and biological alterations in the soil, including mobilization of soil constituents to deeper layers, which could have affected the behaviour of plutonium oxide particles. In this sense, a solubility test using plutonium-weapon-grade-contaminated soils has been designed and performed, using distilled water and cow urine as extracting solutions. The results tend to demonstrate that the addition of cow urine in contaminated soils increases the solubility of plutonium weapon grade. 


\section{OBJECTIVE}

The purpose of this work is to study the temporal evolution of the aqueous solubility of plutonium oxide present in soils from Palomares and the influence of organic fertilizers containing cow urine on the solubility of this radioactive contaminant.

\section{SAMPLES AND METHODOLOGY}

Three soil samples were collected in December 2001 from different zones of the area of Palomares, which is situated to the southeast of Spain in the Almería province (figure 1), where an aerial accident took place in 1966 causing the contamination with plutonium weapon grade of 226 Ha of cultivated, urban and uncultivated areas [6 and 7].

Samples 8T and 27T correspond to the same type of soil (siliceous and carbonated nature); however, sample 43T was collected at the top of a hill formed by slaty material.

Cow urine samples were taken from a dairy farm, $500 \mathrm{~km}$ away from Palomares, in order to avoid the presence of plutonium already incorporated that could lead to false conclusions.

Each soil sample was divided into three $4 \mathrm{~g}$ aliquots, and they were put in contact with distilled water or cow urine solutions (table 1). Room temperature and continuous shaking during 24 hours and 5 days were the main experimental conditions. After that, the solutions were filtrated using $0,45 \mu \mathrm{m}$ Millipore filters. Liquids (urine and aqueous solutions) and solid rests were separately analysed by radiochemical procedures to determine their level of plutonium [8].

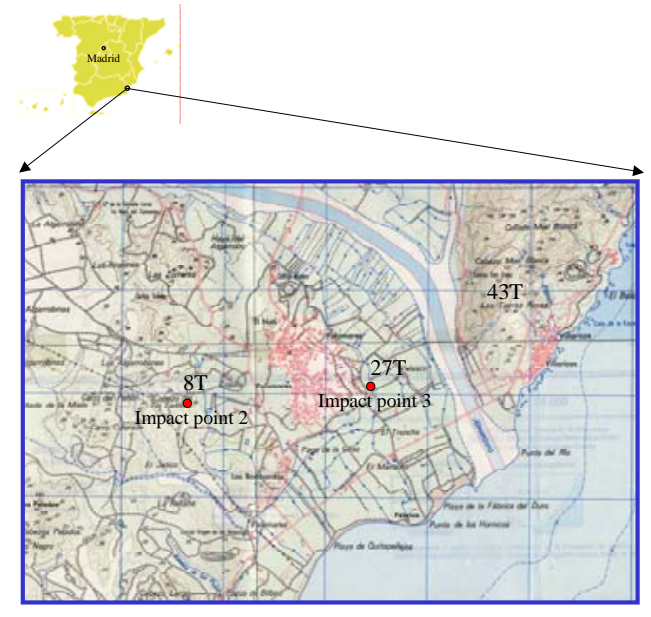

Figure 1. Location of the studied area.

Table 1. Samples and solutions used in the solubility test.

\begin{tabular}{l|cc}
\hline \hline Extracting solution $(\mathbf{6 0 m l})$ & Permanence time & Soil sample reference (4g) \\
\hline Distilled water $(\mathbf{p H}=\mathbf{6 , 5})$ & 24 hours & $8 \mathrm{~T}-1$ \\
Cow urine $(\mathbf{p H}=\mathbf{8})$ & 24 hours & $8 \mathrm{~T}-2$ \\
Cow urine $(\mathbf{p H}=\mathbf{8})$ & 5 days & $8 \mathrm{~T}-3$ \\
Distilled water & 24 hours & $27 \mathrm{~T}-1$ \\
Cow urine & 24 hours & $27 \mathrm{~T}-2$ \\
Cow urine & 5 days & $27 \mathrm{~T}-3$ \\
Distilled water & 24 hours & $43 \mathrm{~T}-1$ \\
Cow urine & 24 hours & $43 \mathrm{~T}-2$ \\
Cow urine & 5 days & $43 \mathrm{~T}-3$ \\
\hline \hline
\end{tabular}




\section{RESULTS AND DISCUSSION}

The measured plutonium activities vary depending on the total sample activity and the extracting solution used (tables 2, 3 and 4).

In all the cases, the percentage of plutonium extracted is higher with cow urine than with aqueous solution. The mechanisms governing the plutonium solubility in cow urine are unknown. The influence of the cow urine $\mathrm{pH}$ should be discarded, based on the results obtained in other solubility tests performed with aqueous solutions with $\mathrm{pH}$ equal to the cow urine $\mathrm{pH}$ [5]. Urea is the main component of the cow urine. This compound is used in the nuclear fuel cycle as a nitrous acid trap in the catalytic redox reactions of actinide ions with formic acid. When decomposition of urea occurs, the actinides are oxidised by $\mathrm{HNO}_{2}$ [9]. Consequently, this process could be responsible for the observed high plutonium solubility in cow urine.

An increase of two orders of magnitude of the plutonium solubility in aqueous solution is observed from 1986 to 2001 (table 5). This fact could be due to the oxidation of plutonium on the surface of $\mathrm{PuO}_{2}$ particles as indicated by other authors [4], because of the agricultural practices carried out on the area and the increase of the specific surface of the plutonium oxide particles due to the fragmentation of the nuclear material [10]. It should be noticed that the high value observed for the plutonium solubility in 1999 was obtained with only one sample, using a filter of $0.70 \mu \mathrm{m}$ to separate the solid rest, instead of the $0,45 \mu \mathrm{m}$ used in the other tests.

The influence of the extraction time with cow urine (24h and 5 days) on plutonium solubility cannot be discussed due to the different agricultural treatments in the analysed soils.

${ }^{238} \mathrm{Pu}$ and ${ }^{239+240} \mathrm{Pu}$ extraction percentages indicate that both isotopes present the same solubility, with a correlation factor of $99,9 \%$.

Table 2. Activity of ${ }^{239+240} \mathrm{Pu}$ and ${ }^{238} \mathrm{Pu}$ extracted with distilled water and acid digestion of residues (LLD=lower limit of detection).

\begin{tabular}{|l|c|c|c|c|}
\hline \multirow{2}{*}{ Sample 8T-1 } & \multicolumn{4}{|c|}{ Extracted activity } \\
\cline { 2 - 5 } & $\mathbf{m B q}$ & \% & mBq & $\%$ \\
\hline Distilled water & $239 \pm 26$ & 0,15 & $3,5 \pm 0,7$ & 0,14 \\
\hline Hot $\left(\mathbf{H F}+\mathbf{H N O}_{3}\right)$ & $154.439 \pm 786$ & 99,85 & $2.462 \pm 99$ & 99,86 \\
\hline
\end{tabular}

\begin{tabular}{|l|c|c|c|c|}
\hline \multirow{2}{*}{ Sample 27T-1 } & \multicolumn{4}{|c|}{ Extracted activity } \\
\cline { 2 - 5 } & $\mathbf{m B q}$ & \% & mBq & $\%$ \\
\hline Distilled water & $12 \pm 2$ & 0,24 & $\leq \mathrm{LLD}$ & \\
\hline Hot $\left(\mathbf{H F}+\mathrm{HNO}_{3}\right)$ & $5.069 \pm 112$ & 99,76 & $86 \pm 15$ & 100 \\
\hline
\end{tabular}

\begin{tabular}{|l|c|c|c|c|}
\hline \multirow{2}{*}{ Sample 43T-1 } & \multicolumn{4}{|c|}{ Extracted activity } \\
\cline { 2 - 5 } & $\mathbf{m B q}$ & $\%$ & $\mathbf{m B q}$ & $\%$ \\
\hline Distilled water & $241 \pm 26$ & 0,15 & $4,2 \pm 0,9$ & 0,16 \\
\hline Hot $\left(\mathbf{H F}+\mathrm{HNO}_{3}\right)$ & $157.312 \pm 578$ & 99,85 & $2.679 \pm 75$ & 99,84 \\
\hline
\end{tabular}


Table 3. Activity of ${ }^{239+240} \mathrm{Pu}$ and ${ }^{238} \mathrm{Pu}$ extracted with cow urine (extraction time $24 \mathrm{~h}$ ) and acid digestion of residues.

\begin{tabular}{|c|c|c|c|c|}
\hline \multirow[t]{2}{*}{ Sample 8T-2 } & \multicolumn{4}{|c|}{ Extracted activity } \\
\hline & $\mathbf{m B q}$ & $\%$ & $\mathbf{m B q}$ & $\%$ \\
\hline Cow urine (24h) & $7.547 \pm 70$ & 2,9 & $122 \pm 9$ & 3,0 \\
\hline Hot $\left(\mathrm{HF}+\mathrm{HNO}_{3}\right)$ & $247.914 \pm 1.177$ & 97,1 & $3.935 \pm 148$ & 97,0 \\
\hline \multirow{2}{*}{ Sample 27T-2 } & \multicolumn{4}{|c|}{$\begin{array}{l}\text { Extracted activity } \\
{ }^{239+240} \mathrm{Pu}\end{array}$} \\
\hline & $\mathbf{m B q}$ & $\%$ & $\mathbf{m B q}$ & $\%$ \\
\hline Cow urine (24h) & $921 \pm 22$ & 14,1 & $18 \pm 3$ & 14,7 \\
\hline Hot $\left(\mathrm{HF}+\mathrm{HNO}_{3}\right)$ & $5.626 \pm 118$ & 85,9 & $104 \pm 16$ & 85,3 \\
\hline \multirow[t]{2}{*}{ Sample 43T-2 } & \multicolumn{4}{|c|}{$\begin{array}{l}\text { Extracted activity } \\
{ }^{239+240} \mathrm{Pu}\end{array}$} \\
\hline & $\mathbf{m B q}$ & $\%$ & $\mathbf{m B q}$ & $\%$ \\
\hline Cow urine (24h) & $2.181 \pm 39$ & 1,7 & $37 \pm 3$ & 1,8 \\
\hline Hot $\left(\mathrm{HF}+\mathrm{HNO}_{3}\right)$ & $122.966 \pm 535$ & 98,3 & $2.053 \pm 69$ & 98,2 \\
\hline
\end{tabular}

Table 4. Activity of ${ }^{239+240} \mathrm{Pu}$ and ${ }^{238} \mathrm{Pu}$ extracted with cow urine (extraction time $5 \mathrm{~d}$ ) and acid digestion of residues.

\begin{tabular}{|c|c|c|c|c|}
\hline \multirow[t]{2}{*}{ Sample 8T-3 } & \multicolumn{4}{|c|}{$\begin{array}{l}\text { Extracted activity } \\
{ }^{239+240} \mathrm{Pu}\end{array}$} \\
\hline & $\mathbf{m B q}$ & $\%$ & $\mathbf{m B q}$ & $\%$ \\
\hline Cow urine (5d) & $2.559 \pm 69$ & 0,5 & $46 \pm 9$ & 0,5 \\
\hline $\mathrm{Hot}\left(\mathrm{HF}+\mathrm{HNO}_{3}\right)$ & $560.964 \pm 4.142$ & 99,5 & $8.985 \pm 524$ & 99,5 \\
\hline
\end{tabular}

\begin{tabular}{|c|c|c|c|c|}
\hline \multirow{2}{*}{ Sample 27T-3 } & \multicolumn{4}{|c|}{ Extracted activity } \\
\hline & $\mathbf{m B q}$ & $\%$ & $\mathbf{m B q}$ & $\%$ \\
\hline Cow urine (5d) & $59 \pm 12$ & 0,6 & LLD & \\
\hline $\mathrm{Hot}\left(\mathrm{HF}+\mathrm{HNO}_{3}\right)$ & $10.365 \pm 228$ & 99,4 & $156 \pm 28$ & 100 \\
\hline \multirow[t]{2}{*}{ Sample 43T-3 } & \multicolumn{4}{|c|}{ Extracted activity } \\
\hline & $\mathbf{m B q}$ & $\%$ & $\mathbf{m B q}$ & $\%$ \\
\hline Cow urine (5d) & $11.323 \pm 141$ & 3,8 & $198 \pm 19$ & 3,9 \\
\hline $\mathrm{Hot}\left(\mathrm{HF}+\mathrm{HNO}_{3}\right)$ & $287.592 \pm 1.723$ & 96,2 & $4.930 \pm 225$ & 96,1 \\
\hline
\end{tabular}


Table 5. Temporal evolution of the solubility of plutonium in water.

\begin{tabular}{|l|c|c|c|}
\hline \multicolumn{1}{|c|}{ Sampling date } & $\begin{array}{c}1986 \\
\text { (Iranzo et al., 91) }\end{array}$ & $\begin{array}{c}1999 \\
\text { (Espinosa, 02) }\end{array}$ & 2001 \\
\hline Number of samples & $\mathbf{5}$ & 1 & 3 \\
\hline $\begin{array}{l}\text { Percentage of }{ }^{239+240} \mathrm{Pu} \\
\text { dissolved in distilled water }\end{array}$ & $0,0082(\sigma=0,006)$ & 0,79 & $0,18(\sigma=0,05)$ \\
\hline
\end{tabular}

\section{CONCLUSIONS}

Addition of manure, containing cow urine, in contaminated soils increases the solubility of plutonium weapon grade dispersed in Palomares.

The solubility in aqueous solution of plutonium weapon grade in Palomares varies with time, showing an increment of two orders of magnitude in 15 years.

In this experiment, the behaviour of the plutonium isotopes analysed $\left({ }^{238} \mathrm{Pu}\right.$ and $\left.{ }^{239+240} \mathrm{Pu}\right)$ follows the same pattern.

\section{Acknowledgements}

We wish to express our appreciation to Dra M. Paz Antón for her suggestions and comments. This work has been partially supported by DOE (USA).

\section{References}

[1] T.J. Martin, E.B. Juniper, 1970. The cuticles of plants. Edward Arnolds, Edinburgh.

[2] S.E. Lindberg, T.P. Meyers, G.E. Jr Taylor, R.R. Turner, W.H. Schoeder. Atmosphere - surface exchange of mercury in a forest: results of modeling and gradient approaches. J. Geophys. Res. 97: 2519-2528, (1992).

[3] H. Marschner. Mineral nutrition of higher plants. Academic press. ISBN 0-12-473542-8 (1995).

[4] J.M. Haschke, Thomas H. Allen and Luis A. Morales. Reaction of plutonium dioxide with water: formation and properties of $\mathrm{PuO}_{2+x}$. Science, vol 287, (14th January, 2000).

[5] A. Espinosa. Tesis doctoral. Comportamiento ambiental de las partículas de combustible nuclear (fundamentalmente Pu) tras un accidente nuclear en un ecosistema de tipo mediterráneo. Madrid, (2002).

[6] E. Ramos y E. Iranzo. Experiencia sobre un caso de contaminación accidental por elementos radiactivos. Second International Civil Defecse. Symposium on Nuclear Radiation Hazards. 1966.

[7] E. Iranzo, A. Espinosa, and C.E. Iranzo. Evaluation of remedial action taken in agricultural area contaminated by transuranides. IV international symposium of radioecology Cadarache France 1988.

[8] A. Aragón, A. Espinosa. Determinación de ${ }^{239+240} \mathrm{Pu}$ en muestras de suelos, Procedimiento específico PRX311. Rev 1 (1996).

[9] 9.-A.-V. Ananiev, V.P. Shilov, I.G. Tananiev, Ph. Brossard, J.C. Broudic. Heterogeneous-catalytic redox reactions in nitrate - Formate, in Proceedings of the International Conference Atalante 2004 (Nimes, France, 2004).

[10] A. Espinosa Canal, A. Aragon del Valle, Berta de la Cruz Cantero and J.A. Fernandez Amigot. Location and isolation methodology of radioactive particles in plutonium and americium contaminated soil. Pre-Conference Workshop ADVANCED TECHNIQUES AND RADIONUCLIDE SPECIATION WITHIN RADIOECOLOGY. IAEA-MEL, Monaco August 30-31 2002 